\title{
La actitud de escucha, fundamento de la comunicación y la democracia en el aula*
}

\author{
J. HUMBERTO MOTTA ÁVILA* \\ Universidad Pedagógica y Tecnológica de Colombia, Colombia \\ mottaavila13@yahoo.com
}

Recepción: 10 de diciembre de 2015.

Aprobación: 10 de mayo de 2016.

Forma de citar este artículo: Motta Ávila, J. H. (2017). La actitud de escucha, fundamento de la comunicación y la democracia en el aula. Cuadernos de Lingüística Hispánica, (30), 149-169. doi: https://doi.org/10.19053/0121053X.n30.0.6192

\footnotetext{
* Artículo de investigación. Presenta un avance de la tesis doctoral intitulada La actitud de escucha en la comunicación pedagógica.

** Doctorando en Lenguaje y Cultura de la Universidad Pedagógica y Tecnológica de Colombia; integrante del Grupo de Investigación EPISTEME; actualmente, profesor de la Escuela de Idiomas de la Uptc.
} 


\title{
Resumen
}

El artículo busca dar cuenta de la actitud de escucha de estudiantes y docentes como fundamento de la comunicación y la democracia en el aula de clases. Presenta una síntesis del diagnóstico actual de la escucha áulica, y los referentes teóricos que sustentan la relación escucha-comunicación-democracia. El proceso metodológico está basado en las tradiciones fenomenológica y hermenéutico-reflexiva. Como resultado, se explica que el acto de escucha es condición indispensable del acto pedagógico de aula, que la escucha ha devenido en disonancia y déficit de la democracia y en la esencia de la conversación democrática.

Palabras clave: actitud de escucha, comunicación pedagógica, experiencia de la democracia en el aula, acto de escucha.

\section{Listening Attitude as a Foundation for Communication and Democracy in the Classroom}

\begin{abstract}
This article seeks to illustrate the listening attitude of students and teachers as a foundation for communication and democracy in the classroom. It presents a synthesis of the current diagnosis on classroom listening, as well as the theoretical referents that support the listening-communication-democracy relation presented in this study. The methodological process is based on the traditions of phenomenology and reflexive hermeneutics. As a result, the act of listening is developed an essential condition for classroom pedagogy. This implies the need to keep listening attitudes away from dissonance and degradation, understanding its importance for a democratic approach to conversation.
\end{abstract}

Key words: listening attitude, pedagogical communication, classroom democratic experience, act of listening. 


\section{L'attitude d'écoute, fondement de la communication et de la démocratie dans la salle de classe}

\section{Résumé}

L'article cherche à rendre compte de l'attitude d'écoute des étudiantes et des enseignants comme fondement de la communication et de la démocratie dans la salle de classe. Il présente une synthèse du diagnostic actuel de l'écoute en classe, et les référents théoriques qui soutiennent le rapport écoute-communication-démocratie. Le processus méthodologique se base sur les traditions phénoménologique et herméneutique-réflexive. Comme résultat on explique que l'acte d'écoute est une condition indispensable de l'acte pédagogique de la salle de classe, que l'écoute a engendré la dissonance et le déficit de la démocratie et l'essence de la conversation démocratique.

Mots clés: attitude d'écoute, communication pédagogique, expérience de la démocratie dans la salle de classe, acte d'écoute.

\section{A atitude de ouvir, a base da comunicação e da democracia na sala de aula}

\section{Resumo}

0 artigo procura explicar a atitude de escuta dos estudantes e dos professores como base para a comunicação e a democracia na sala de aula. Ele apresenta uma síntese do diagnóstico atual de escuta de classe e as referências teóricas que apoiam a relação ouvindo-comunicação-democracia. 0 processo metodológico baseia-se em tradições fenomenológicas e hermenêuticas-reflexivas. Como resultado, é explicado que o ato de ouvir é uma condição indispensável do ato pedagógico em sala de aula, que a escuta se tornou dissonância e déficit de democracia e a essência da conversa democrática.

Palavras-chave: atitude de escuta, comunicação educacional, experiência da democracia na sala de aula, ato de ouvir. 


\section{Introducción}

La acogida que está teniendo en la actualidad la investigación sobre el fenómeno de la escucha humana, lleva a colegir que se están encontrando razones poderosas que la justifican, entre las que se destacan: en el contexto de la democracia, la escucha se está percibiendo como una disonancia y un déficit en la construcción ciudadana (Bickford, 1996); la era tecnológica ha creado las condiciones para una cultura del ruido que está dejando consecuencias funestas en la salud física y mental de las personas (Marco, 2009); la mayor parte de los conflictos entre las personas (niños, jóvenes y adultos) y en las instituciones sociales son causados por el bajo desarrollo de la competencia para la escucha (Torralba, 2007); esta habilidad lingüística recibe poco o nulo tratamiento en la familia, la escuela y la sociedad (Echeverría, 2007); la mayor parte del fracaso escolar no radica en la incompetencia del estudiante, sino en el desconocimiento de las bondades que el desarrollo de la escucha le aporta al logro académico (Tomatis, 1996); se pasa por alto que, antes de hablar, leer y escribir, la biología del ser humano partió de la escucha para sentar las bases del lenguaje y que es el acto de escucha el que determina el acto de habla, de lectura y de escritura.

Como se ve, el estudio de la escucha en los ámbitos escolar y social es un campo muy prometedor para la investigación científica y para la intervención pedagógica. Por esto, en el contexto problemático descrito, ha surgido la presente investigación que la explora en el seno del aula ${ }^{1}$, para develar su sentido. Como puede inferirse, se trata de un estudio fenomenológico del acto de escucha en el contexto escolar, con implicaciones para la calidad de vida social en el espacio áulico.

Ahora, en el marco de esta investigación, el presente artículo constituye un avance en el análisis de la información, resultado de la aplicación de la técnica de observación cualitativa, la cual fue directamente realizada en el aula por el mismo investigador, no participante, estructurada, de campo e individual. Los grupos clase observados correspondieron a aquellos en los que el investigador tuvo acceso en su condición de asesor de práctica pedagógica de los maestros en formación de la Licenciatura en Idiomas Modernos de la Uptc. Los instrumentos de registro de la actitud de escucha fueron el diario de campo, el

1 La investigación inició en el año 2013 y se extendió hasta 2016. La observación se llevó a cabo en cuatro instituciones educativas públicas de Tunja. 
formato guía para la observación de la actitud de escucha, la sección de notas y reflexiones sobre aspectos relacionados con la escucha de la guía para la observación de clases, grabaciones de audio y de video. El método empleado para el procesamiento y análisis de la información fue la hermenéutica reflexiva, planteado por Ríos (2013) y que se muestra en los aspectos metodológicos. El análisis está dirigido a la relación existente entre la actitud de escucha, la comunicación pedagógica y la experiencia democrática en el aula de clases.

\section{Síntesis del diagnóstico de la escucha áulica}

Bastará con preguntarle a cualquier docente de educación básica o media por el aspecto más difícil de sortear en el aula de clase, para enterarse de que, salvo contadas excepciones, tiene que ver, de alguna manera, con la actitud de desescucha de los estudiantes frente a la conversación pedagógica de aula. Esto ha estado sucediendo en concomitancia con el advenimiento de la escuela primaria y la escuela secundaria como instituciones de socialización -en el sentido degradado de habitarla con fines de solo amiguismo y "parche" para dejar que el tiempo pase- y de guardería (Marco, 2009) -en el sentido de espacio para dejar a los hijos al cuidado de los profesores-, en detrimento del sentido propio de escuela como lugar para la construcción de la cultura académica, que es la vía regia para el desarrollo humano y social. Las consecuencias funestas de esta realidad se viven en todas las geografías locales y regionales de Colombia, junto a políticas educativas con las que el sentido de la responsabilidad y la libertad, y el valor del esfuerzo, se han venido a menos.

En tal estado de cosas, establecer una conversación pedagógica en el aula, a propósito del conocimiento y la cultura, en la vía del desarrollo personal y colectivo, no es una prioridad de los sujetos educativos, incluido el docente, quien ha tenido que adaptarse a las condiciones imperantes y trazarle otros horizontes a su compromiso laboral, habida cuenta de la diversidad de asuntos que ocupan el pensamiento y la acción de los niños y jóvenes de hoy, resultado de la tecnologización de la vida. Estos asertos llevan a concluir que la conversación pedagógica y la experiencia de la democracia en el aula no se dan como debieran.

De otra parte, quienes se han interesado por estudiar el fenómeno de la escucha, dejan ver en sus argumentos esta aguda crisis: "El escuchar, la habilidad lingüística olvidada" (Segura, 2010, p. 1); "Estudios realizados han constatado que de las habilidades comunicativas, la que más se practica es la de escuchar, pero contradictoriamente en la escuela no se ejercita suficientemente" (Aguilar, 2007, p. 1);

A través del palabrerío me parece está escondido éste espíritu de sordera que impide el encuentro con los otros, porque el que está atacado por este espíritu 
de disconformidad, que es la akedia, en realidad lo que le hace es no dejarlo permanecer en un lugar con alguien, con otros (Grün, citado en Ubini, 2007, p. 4).

«Y cuando lo que se ha dicho no es escuchado en la forma esperada, la gente llena esta "brecha crítica" con historias y juicios personales acerca de cómo son las otras personas, produciendo problemas todavía más profundos en la comunicación» (Echeverría, 2007, p. 145). "[...] actualmente se erige triunfante en nuestra sociedad, globalizadora, esa conducta de la incontinencia verbal, auténtica babel de ruidos indescifrables, donde todos hablan y nadie escucha" (Marco, 2009, p. 32). Como puede verse, esta muestra de asertos anuncia la existencia de un problema y el olvido de su tratamiento y solución.

Igualmente, el cambio del sentido y de la acción de escuchar actual con respecto a la pedagogía tradicional, permite apreciar la problemática:

No se puede hacer una historia de la enseñanza del arte de escuchar. Es un arte cuya importancia y dificultad se han desconocido durante siglos. Los pedagogos de todos los tiempos creyeron que bastaba reunir a los alumnos en una sala y hacerlos callar para que asimilaran al momento todos los discursos que ante ellos se pronunciaban. Este error pedagógico ha perjudicado siempre mucho a la comunicación en la enseñanza. Sólo hoy se comienza a investigar para repararlo (Gauquelin, 1972, p. 55).

Esta sencilla muestra de argumentaciones y la información proveniente del diagnóstico de aula realizado (ver tabla 2), develan la necesidad de dar un giro en los estudios del lenguaje hacia la investigación de la escucha, pues no solo es la puerta de entrada al lenguaje humano, sino la que determina las demás habilidades lingüísticas básicas: hablar, leer, escribir. En suma, la escucha es la habilidad fundante de los actos del lenguaje, puesto que antes de hablar, leer o escribir, el ser humano ha activado la facultad del lenguaje y estructurado su sistema de comunicación que es básicamente oral, a partir de los procesos de audición y escucha.

\section{Referentes teóricos}

En la senda de dar cuenta de que sin educación de la escucha es poco probable que los sujetos escolares lleven a cabo su proyecto de interacción comunicativa y experimenten la vida en democracia, se tratan en seguida tres aspectos: primero, un marco conceptual que pone en escena los conceptos de actitud de escucha, comunicación pedagógica y experiencia de la democracia, que son básicos para el artículo; segundo, la argumentación de que el acto pedagógico es un acto comunicativo en el que el acto de escucha es conditio sine qua non pueda darse; y tercero, una argumentación que expone la escucha como di- 
sonancia y déficit en la democracia, y, en contraparte, la escucha como factor determinante de la conversación democrática.

Siguiendo el orden anunciado, en primer lugar, es menester hacer el tratamiento de tres conceptos centrales: actitud de escucha, comunicación pedagógica y experiencia de la democracia.

En esta investigación, el concepto "actitud de escucha" requiere conocer los conceptos de "actitud" y de "escuchar". Ahora, siendo escuchar un concepto complejo, puesto que habita diversos campos disciplinares (lingüística, semiótica, música, filosofía, psicología, psicoanálisis, pedagogía...), para el interés de este trabajo, se ha elegido una perspectiva lingüística y semiótica desde la concepción de Lynch y Mendelsohn (citados en Schmitt, 2002), quienes afirman lo siguiente:

Escuchar implica tener sentido del lenguaje hablado, normalmente acompañado de otros sonidos y estímulos visuales, con la ayuda de nuestro conocimiento previo pertinente y el contexto en el que estamos escuchando. Sin embargo, en lugar de pensar en la escucha como un solo proceso, es más preciso concebirlo como un conjunto de procesos relacionados -reconocimiento de los sonidos emitidos por el orador, la percepción de los patrones de entonación que muestran el foco de la información, interpretación de la relevancia de lo que se dice en el tema actual, y así sucesivamente. (p. 193). ${ }^{2}$

Es decir, escuchar es un proceso interpretativo que, desde la postura del investigador y del tema, requiere por parte del escuchante 0 escuchador un compromiso ético con el interlocutor, materializado en el reconocimiento del otro como interlocutor válido. En el contexto de aula, escuchar hace referencia a una disposición de los sujetos de la conversación pedagógica (maestro-estudiante y estudiante-estudiante) para poner en circulación su sentir, su pensar y su actuar, en beneficio de su propio desarrollo humano. Es decir, antes de saber escuchar, es primordial que los sujetos hayan habitado previamente la estancia de una educación para la escucha activa. Sin esta, una sociedad (una humanidad determinada, la del aula) no podrá contar con "escuchadores competentes". iY la institución educativa es un escenario para el desarrollo de la pedagogía de la escucha!, y para el distanciamiento de la vida ordinaria.

Siguiendo, se presenta la noción de actitud, con miras al tratamiento de la unión semántica de los dos conceptos, id est, "actitud de escucha”. En cuanto el concepto de

2 Traducción del autor. 
actitud, desde la psicología puede presentarse, entre las tantas nociones ${ }^{3}$, la que plantean Eagly y Chaiken (citados por Albarracín, Johnson y Zanna, 2005), considerada la definición más convencional: "Una actitud es una tendencia psicológica que se expresa mediante la evaluación de una entidad particular con algún grado de aprobación o desaprobación" (p. 4). Ahora, si la manera preferencial de respuesta tiene un valor negativo, viene el conflicto propio de la vida de relación, visto que el aula es un ambiente para esa vida. Así, la adopción de este concepto se muestra prometedora para la construcción de nuevos sentidos de los conceptos restantes de este marco, principalmente, el de desescucha que es la contraparte del valor ético que tiene el de actitud de escucha.

Ahora sí, con base en los dos anteriores conceptos, es posible hablar de actitud de escucha. Si bien la expresión se encuentra codificada en la literatura especializada, no recibe el tratamiento al que aspira esta indagación. Acá, la "actitud de escucha" deviene una postura ética y política en los sujetos discursivos del aprendizaje y de la enseñanza frente al proceso de la comunicación pedagógica, pues dependiendo de si es una actitud positiva o negativa contribuye o no con la construcción de sujetos discursivos para la ciudadanía y la democracia. Por esto, la actitud de escucha debe formar parte de las competencias actitudinales básicas del estudiante. En este orden de ideas, para enriquecer el concepto se hace mención de tres aportes: Rice (2011), quien al plantear una concepción aristotélica de la buena escucha, concluye que esta puede ser considerada como una virtud; Laverty (2011) basada en la concepción rousseauniana de la comunicación sostiene que la escucha desempeña un papel central en la comunicación "porque es en el acto de escucha que los seres humanos satisfacen o fracasan en el imperativo de entender a los demás" ${ }^{4}$ (p. 155); y Waks (2011) resalta en la propuesta educativa de Dewey la estrecha conexión entre escucha y democracia a partir de los conceptos de escucha de una vía y escucha transaccional, siendo esta última la que "genera una actitud de amistad cooperativa que reposa en el corazón de la democracia" (p. 204). Estos argumentos permiten apreciar la importancia

3 Los psicólogos no acogen una definición concreta de actitud, sino que, por lo general, cada uno propone la suya. Así, como ejemplos, se presentan las siguientes: Kimball Young: "Se puede definir una actitud como la tendencia o predisposición aprendida, más o menos generalizada y de tono afectivo, a responder de un modo bastante persistente y característico, por lo común positiva o negativamente (a favor 0 en contra), con referencia a una situación, idea, valor, objeto o clase de objetos materiales, 0 a una persona o grupo de personas"; "una organización duradera de creencias y cogniciones en general, dotada de una carga afectiva a favor o en contra de un objeto definido, que predispone a una acción coherente con las cogniciones y afectos relativos a dicho objeto"; David G. Myers: "Actitud es la reacción evaluativa, favorable o desfavorable, hacia algo o alguien, que se manifiesta en las propias creencias, sentimientos o en la intención; John C. Maxwell: "La actitud es un sentimiento interior expresado en la conducta".

Coinciden sí en que las actitudes tienen los siguientes tres componentes: cognoscitivo, afectivo o emocional y conductual; además, en que una vez formada la actitud en el esquema comportamental del sujeto, es realmente difícil que se modifique, pues muchas creencias, convicciones y juicios se remiten al seno familiar, por lo que se hace indispensable una intervención pedagógica y social que le permita - al estudiante- hacer la distinción entre una forma de ser y otra, más favorable para su vida personal y colectiva. 
que tiene la actitud de escucha en la educación de los seres humanos, puesto que esta es una virtud dirigida a entender a los demás, comunicativamente, con lo cual contribuye al fortalecimiento de la democracia.

Ligado con lo anterior, está el concepto de desescucha, no codificado en el mundo académico, por lo que el investigador está construyendo su sentido con miras a dar cuenta de una realidad atinente a la dinámica del fenómeno general de la escucha. Este se refiere al desvalor de la actitud de escucha. No atañe en sí a una deficiencia de orden psicológico ni a alguna disfunción neurológica del sistema auditivo, sino a expresiones de carencias de orden social y cultural ${ }^{5}$ frente al compromiso de escuchar al otro. La desescucha viene a ser más un meme ${ }^{6}$ (Dawkins, 2000; Ridley, 2001; Bauer, 2008) introyectado por las prácticas sociales degenerativas, no constructivas, un pacto inconsciente que lleva a los sujetos a acogerse a la costumbre de desescuchar, a evitar el compromiso ético y político frente al interlocutor; en el fondo es la negación del otro, el no reconocimiento del decir del otro. En el paso de la escuela del mutismo a la escuela del bullicio puede verse el desarrollo de dicho meme. Lentamente, se fue acomodando la costumbre de desescuchar hasta hacerse una forma de acción comunitaria. En el fondo, constituye una ruptura de paradigma: de los grupos de estudiantes en mutismo ${ }^{7} \mathrm{y}$ amedrentados, a los grupos bulliciosos y temerarios. Cabe aclarar que tanto la actitud de escucha como la desescucha han estado siempre en la vida social y en la vida de la escuela. El pedagogo y moralista clásico Plutarco (1985) da noticia de este hecho en su tratado Sobre cómo se debe escuchar: "Pues un oyente pesado y molesto es aquel hierático e insensible a todo lo que se dice, lleno de una pérfida presunción y de una fanfarronería innata, como si pudiera decir algo mejor que lo que se está diciendo [...]" (p. 182).

De otra parte, en cuanto la asunción del acto pedagógico como acto comunicativo, en el que el acto de escucha -como acto performativo de doble vía, pues hablar hace al interlocutor escuchar y escuchar hace al interlocutor hablar- valida el habla tanto del

5 Es importante advertir que hay sociedades y culturas más escuchadoras que otras; por ejemplo, es reconocido el valor de la escucha entre los japoneses, pero no mucho entre los colombianos, en donde lo político, lo social, lo educativo y la salud, entre otros, son un homenaje a la desescucha: se deja hablar (reclamar, protestar...) para aparentar democracia, pero no se actúa proactivamente frente a los reclamos y protestas: se hace oídos sordos, se entiende, pero no se escucha.

6 Dawkins, en su obra El gen egoísta, propone el término para dar a entender lo que es "una unidad teórica de información cultural transmisible de un individuo a otro, o de una mente a otra, o de una generación a la siguiente”. Mark Ridley (2001) y Joachim Bauer (2008) reformulan el concepto al sustentar que lo que se ha dado es más la perspectiva cooperativa de la evolución biológica y cultural. Así, deberá entenderse acá el meme como una unidad teórica cooperativa de replicación cultural que orienta las prácticas sociales de una determinada comunidad. En este orden de ideas, la desescucha se ha vuelto una práctica acostumbrada en la vivencia del aula por los grupos clase.

7 Se prefiere el uso del concepto de en mutismo y no de silenciosos en razón del sentido que se quiere dar a este último como valor personal y social en la actividad escolar. Tal sentido se expone en Motta (2016). 
que enseña como del que aprende, es necesario optar por una comprensión del lenguaje pedagógico como polifonía, como voces en concierto: la del docente, la de los estudiantes, la del conocimiento, la del contexto áulico. Habermas (1996) dice que "el lenguaje disociado de su uso comunicativo, es decir un lenguaje completamente monológico no puede pensarse consistentemente como lenguaje" (p. 61). Esto ligado al proceso pedagógico y a la comunicación pedagógica, hace la exigencia de lo dialógico, de lo conversacional, de lo intersubjetivo: la conversación pedagógica.

Complementariamente, Young (1993) propone una pedagogía que haga del lenguaje el elemento central para llegar a la comprensión de las situaciones problemáticas de la enseñanza y de la interacción docente-estudiante. Por eso, propone la clase discurso, en la que el estudiante se convierte en un interlocutor pedagógico válido y en un coinvestigador al lado del maestro y los demás integrantes del grupo clase. En definitiva, el ejercicio ético político de la escucha conduce indefectiblemente a la opción de una pedagogía del conversar $^{8}$, cuyos principios iluminadores fundamentan no solo la comunicación pedagógica, sino la experiencia de la democracia. Tales principios son: el diálogo igualitario, que apunta a las aportaciones en función de la validez de los argumentos y no por las posiciones de poder de quienes lo realizan; la inteligencia cultural, que considera que todos tienen las mismas capacidades para participar en un diálogo igualitario, aunque cada quien pueda demostrarlas en ámbitos distintos; la transformación relacional, que asume que el aula de clase es un escenario de conflicto y que, por lo tanto, es necesario que los sujetos del aprendizaje y de la enseñanza se den a la tarea de realizar diálogos constructivos que transformen las relaciones interpersonales y el entorno mismo; el uso de la técnica instrumental como enriquecimiento del aprendizaje dialógico, pues hoy es poco probable que un encuentro pedagógico sea exitoso en ausencia de las TIC, y demás recursos de apoyo; el reto constante con la re-creación del sentido, visto que la validez del conocimiento es provisional y se hace necesario actualizar su valor de verdad en el aula; espacios de senderos solidarios, en razón de que las prácticas educativas y sociales solo pueden fundarse, para su desarrollo y fomento, en concepciones y realizaciones solidarias: en el aula, "uno para todos y todos para uno"; la igualdad en las diferencias, ya que una pedagogía de la escucha para la conversación afirma que la verdadera igualdad implica el mismo derecho de toda persona a ser y a vivir de forma diferente.

Como puede verse, en la comunicación pedagógica, la pedagogía del conversar, que deviene en pedagogía de la escucha, es una estrategia para la construcción de sujeto,

8 Una adaptación del investigador con base en lo expuesto por Rafael Lucio Gil, en: Del aprendizaje significativo al aprendizaje dialógico. 
sociedad democrática y saberes. Contribuye, al mismo tiempo, a que la sociabilidad en el aula llegue a ser la forma superior de la intersubjetividad y un modo de habitar la vida cotidiana (Schütz, 1979). La ausencia de los principios mencionados y de esta orientación fenomenológica, ha generado la crisis de comunicación que se vive en muchas aulas (ver tabla 2). Esta situación la describe profusamente Marco (2009), sobre cuya crítica queda el reto de un nuevo quehacer estudiantil y docente.

Finalmente, se cierra este apartado con la exposición de la escucha como disonancia y déficit en la democracia y como factor esencial de la conversación democrática, para, luego, proyectar estas ideas a la vida de la escuela y el aula de clase. Para empezar, se ponen en escena los argumentos de Bickford (1996) y Dobson (2012). Estos autores coinciden en mostrar que las democracias contemporáneas han hecho énfasis en que tener la palabra (hablar) u otorgarla constituye factor para la manifestación de la ciudadanía, pero poca atención le han prestado a la escucha (escuchar y ser escuchado) como una forma más refinada de vivir la democracia. En tal sentido, Bickford prueba que la escucha tiene implicaciones profundas para el ejercicio de la ciudadanía democrática en un orden social diverso y desigual, y Dobson afirma que la teoría y la práctica de la democracia pueden ser re-vigorizadas mediante la atención prestada a la escucha. De estos asertos, es posible inferir que, en la vida política de las actuales democracias, la escucha debería ser una condición indispensable para la expresión de este modo de organización social, pero, infortunadamente, ha sido ignorada, y maquiavélicamente hablando, esta negativa a escuchar está siendo empleada como una forma eficaz e insidiosa de silenciar las voces de la crítica, del reclamo o de la solicitud. Esto, entonces, lleva a colegir que la escucha, en relación con la política, constituye una disonancia, puesto que no hay conformidad entre la teoría y la práctica de la democracia, y constituye, a la vez, un déficit porque, siendo tan necesaria, no se cultiva en el seno social. He aquí el advenimiento de la desescucha como actitud de negligencia en la vida política. Es una epidemia hecha de memes -"unidades de información discreta de herencia cultural" a manera de buenos o malos "replicadores culturales" (Santibáñez, 2011, pp. 3-4) - que le permite a una organización política de un país dejar hablar cuanto quieran los agricultores, o los maestros, o los estudiantes, o las comunidades originarias, o los ancianos pensionados, ya que efectivamente al final nada les será atendido. Acá, el poder es de los "oidores" -en estado de marasmo-, no de los escuchadores, que, como se ha venido argumentando, tiene implicaciones éticas y verdaderamente políticas.

Subsecuentemente, como factor esencial de la conversación democrática, la escucha, según Dobson (2014), es una parte clave de lo que es comunicar, y, además, le otorga al escuchador un poder, similar al igual de quien tiene la palabra, porque cuando se habla, 
los hablantes están en dependencia de los escuchadores para el logro comunicativo, no al contrario (en los eventos electorales, iel poder lo tienen los que escuchan!, puesto que quien define el futuro del político es el que escucha y, en consecuencia, decide). "Así que la negación de la escucha es una expresión de poder, ser escuchado es una atribución de poder" (p. 22). Por esta razón es que, como se dijo antes, la escucha determina el habla y en la comunicación el éxito de la misma lo define el nivel de competencia para la escucha que posean los interlocutores.

De este modo, un modelo de comunicación centrado en la escucha implica una exigencia ética (de relación) y estética (de valoración sensible) a la retórica del hablante quien deberá esmerarse en la estética del habla para convocar la estética de la escucha en su interlocutor: el que escucha disfruta el hablar, como el que habla disfruta el escuchar. Porque cuánta frustración hay al proferir un mensaje y encontrar que no se lo ha recibido o que se lo ha tergiversado. He aquí el papel protagónico de la actitud de escucha en el marco de la comunicación humana que deberá ser ante todo una actividad basada en una perspectiva democrática que es, al mismo tiempo, una perspectiva educativa (compromiso con la verdad, la bondad y la belleza), un asunto de la cultura, un definir los sentidos de cómo ha de circular la democracia en una sociedad determinada. En esto, la escuela tiene mucho que hacer.

\section{Aspectos metodológicos}

En términos generales, la metodología empleada es fundamentalmente cualitativa. Se ha elegido el enfoque investigativo cualitativo de corte comprensivo interpretativo, dadas sus bondades para el tratamiento del fenómeno del escuchar humano en el contexto educativo, puesto que: permite la pluralidad metódica; resalta la información obtenida naturalmente, no mediante técnicas prefabricadas; registra el mundo desde la experiencia de los sujetos que se estudian; se aleja de la postura positivista; y aplica la indagación inductiva, entre otras.

Dentro de este enfoque, se ha optado por las tradiciones investigativas fenomenológica y hermenéutico reflexiva. La primera por la importancia que le da a la significación y a los sentidos que los sujetos le otorgan a la experiencia vivida; y la segunda, por constituirse en un estilo innovador de investigación cualitativa que consiste en un encuentro de las propuestas de análisis de Ricoeur, Geertz y Schutz, como lo hace Ríos (2013).

En cuanto la fenomenología, es un movimiento filosófico que es a la vez un método y una teoría. En palabras del mismo Husserl (citado en Bolio, 2012), 
La fenomenología designa un nuevo método descriptivo que hizo su aparición en la filosofía a principios del siglo [XX] y una ciencia apriorística que se desprende de él y que está destinada a suministrar el órgano fundamental para una filosofía rigurosamente científica y posibilitar, en su desarrollo consecuente, una reforma metódica de todas las ciencias (pp. 20-29).

Respecto del tema filosófico trascendental, para Husserl, no es la búsqueda del ser, sino de lo que él denomina objetos intencionales, esto es, "objetos asumidos por la subjetividad o la intersubjetividad. No mira hacia el mundo, sino hacia mundos posibles desarrollables, a partir de los fines del sujeto individual o colectivo" (Bolio, 2015, p. 23). Este modo de filosofar, entonces, parte de la idea de que el mundo percibido por el sujeto no es algo determinado y acabado, sino algo construido y cambiante, modificado por el mismo sujeto que le otorga la significación desde su particular espectro de experiencias. De esta forma, la experiencia objetiva no llega a ser una realidad, porque en la interacción del sujeto con el objeto o en la vivencia del fenómeno, estos quedan impregnados de los sentidos de quienes los experimentan. Como lo expresan Maykut y Morehouse (1999), "el enfoque fenomenológico tiene como foco entender los significados que tienen los eventos para las personas que serán estudiadas" (p. 3). Tal cúmulo de experiencias es lo que, fenomenológicamente hablando, constituye la realidad, la cual está indefectiblemente enmarcada por los componentes del contexto en el que está inmerso el sujeto.

En este orden de ideas, el estudio fenomenológico del escuchar áulico parte de la concepción de este como un acto intencional (noesis) al que le corresponde la escucha como objeto intencional (noema o cogitatum). El escuchar y la escucha así entendidos y puestos en circulación en la experiencia de la conversación pedagógica de aula, revelan una intencionalidad en los sujetos educativos que la vivencian: se escucha con un propósito, como también hay propósito en la desescucha; y tales intencionalidades permiten acceder a su sentido.

Concomitantemente, dada la existencia de diversas tradiciones dentro de la propuesta fenomenológica de investigación, el investigador ha elegido complementar esta con la tradición hermenéutica reflexiva a la que la investigadora chilena Teresa Ríos Saavedra le hace una adaptación metodológica original que cumple con los requerimientos de un proceso científico en investigación educativa. Según Ríos (2005), la hermenéutica reflexiva puede constituirse en "un nuevo estilo de investigación cualitativa el cual ofrecería una convergencia que complementa los aportes de otras investigaciones que abordan las problemáticas emergentes en el sistema educativo" (p. 51). Tal estilo, circunscrito en el enfoque comprensivo interpretativo que ofrece la hermenéutica, consiste en "una articulación entre la hermenéutica reflexiva de Paul Ricoeur y la antropología hermenéutica de Clifford 
Geertz, cuyo puente es un método reflexivo fenomenológico inspirado en la actitud fenomenológica de Alfred Schutz" (p. 51). Y agrega: "Esta combinación de elementos abre un camino develador de sentidos que permanecen encubiertos en las acciones y los discursos de los sujetos investigados" (p. 51).

En suma, para el desarrollo del diseño metodológico basado en la hermenéutica, Ríos sigue tres etapas generales que se siguieron para el procesamiento de la información: primera, aplicación de la propuesta hermenéutica reflexiva de Ricoeur: el análisis estructural del relato, con base en Greimas (explicación); segunda, articulación metodológica desde la hermenéutica hasta la antropología de Geertz (2003): la descripción densa (interpretación y comprensión de los sujetos); y tercera, aplicación del método reflexivo de Schutz (2003): actitud fenomenológica y reducción fenomenológica como actividad reflexiva de la conciencia que representa el modo de la actitud científica.

La recolección de la información se realizó en una población constituida por cuatro instituciones educativas públicas de Tunja; la muestra 0 grupos clase observados correspondieron a aquellos asignados por docentes titulares de las instituciones educativas públicas de Tunja que regularmente acogen a los maestros en formación para la realización del componente práctico de las asignaturas de Didáctica y Práctica de la Lengua Materna que orienta semestralmente el investigador ${ }^{9}$. Los grupos y docentes titulares, en algunos semestres se mantuvieron, pero en otros, se presentaron modificaciones. Estos aspectos no afectaron en sí la observación del fenómeno de la escucha, mas bien brindaron la ocasión de contrastar idiosincrasias grupales y de aumentar la muestra poblacional para enriquecer la información, permitiendo, a la vez, la diversidad topológica y el equilibrio en los atributos y en la dispersión demográfica. La observación estructurada se llevó a cabo durante los años 2013, 2015 y 2016, con el seguimiento del protocolo ético materializado en los debidos permisos de los rectores y docentes de los grupos clase, y con el consentimiento informado para padres de familia y estudiantes.

Ahora, para el propósito del presente artículo, y dada la importancia que tiene la observación cualitativa en este estudio, es preciso caracterizar la que se empleó. Esta fue así: fenomenológica, directa (recolección de la información in situ), no participante (en el sentido de no involucrarse el investigador en las actividades del grupo que se observa, por lo que se limita a mirar y registrar), estructurada o sistemática, de campo, individual,

9 Por efecto de la asignación académica, el investigador permanentemente hace incursión en el aula de clases de secundaria, con el propósito de observar para asesorar el desempeño de los maestros en formación del Programa Idiomas Modernos de la Uptc. En el momento en que se escribe este artículo, orienta las asignaturas Didáctica de la Lengua Materna, Práctica I de la Lengua Materna y Práctica Pedagógica Investigativa de Profundización, ubicadas, respectivamente, en los tres últimos semestres de la carrera. 
obtenida a partir de registros en: la ficha de observación, diario de campo, grabadora de audio y videocámara. A la vez, se siguió la orientación de Ríos (2013) para quien la observación fenomenológica debe ser interpretativa, reflexiva de las acciones humanas que son, al tiempo, acciones simbólicas, esto es, que significan algo de alguien o de algo. La observación como

un estilo de estar en el campo, que se caracteriza por la tensión que se experimenta [...] entre la proximidad y la distancia que se debe mantener en la actitud observadora, pues en el transcurso de las observaciones se transita entre la empatía y el extrañamiento que se generan en las relaciones sociales establecidas en el lugar de la investigación (p. 108).

Shutz (1979) llama a esto actitud desinteresada. El observador es así un lector crítico que busca adentrarse en el sentido de las acciones humanas.

Ahora, en lo atinente al procedimiento para la observación, se siguió la siguiente secuencia de pasos:

1. Determinación del fenómeno o evento de observación: la actitud de escucha de los estudiantes en el aula de clase. 2. Determinación de los objetivos de la observación: - registrar información primaria que deje ver el comportamiento de la actitud de escucha de los estudiantes en el aula de clase y - registrar información de primera mano que permita develar los sentidos que le confieren a la escucha áulica, tanto estudiantes como docentes. 3. Determinación de la forma de registro de la información: anotaciones en la ficha de observación, anotaciones en el diario de campo, grabaciones de audio de las sesiones de observación, grabaciones de video de algunas sesiones de observación. 4. Observación cuidadosa y crítica: la labor de observación estuvo basada no solamente en orientaciones metodológicas, sino en el cuerpo teórico, lo cual le otorga el rasgo de observación científica. El acto de observar así, no es un ejercicio ingenuo sino rigurosamente planeado. 5. Registro de los datos observados: el investigador registró información, resultado de la observación, en la ficha y en el diario de campo; igualmente, en las grabaciones de audio y de video. 6 . Análisis e interpretación de los datos: la ficha de observación contiene aspectos propios de un análisis e interpretación inmediatos de lo observado. 7. Elaboración de conclusiones: igualmente, la ficha de observación contiene el aspecto de las conclusiones resultantes del análisis y la interpretación. 8. Elaboración del informe de observación: el presente artículo constituye, precisamente, una forma de presentación de dicho informe.

La ficha o formato de observación que se empleó para la recolección de los datos, ha sido elaborada a partir de las aportaciones teóricas relacionadas con el estudio de las actitudes y con la síntesis de los elementos indicados por Willig et al. (citados en Hernán- 
dez, Fernández y Baptista, 2010). Este instrumento contiene al mismo tiempo una escala de valoración de los indicadores de la actitud de escucha, componente que permitió ir conformando el perfil de actuación en cada grupo clase.

\section{Resultados}

Se parte del análisis de un corpus de registros de observación fenomenológica que contiene muestras del inicio del proceso de incursión formal del investigador en el aula, hasta la saturación de la información mediante esta técnica. Dicho esto, se pasa a mostrar los resultados mediante la determinación de cinco categorías cualitativas de grupos clase (GC, en adelante) resultantes del análisis de la información contenida en la guía de observación de la actitud de escucha y la guía de observación de clases. De estas cinco, se han seleccionado las dos primeras para el propósito del presente opúsculo, en virtud de que los indicadores de las tres restantes están contenidos en estas. Las categorías que han emergido son: el GC escuchador, el GC desescucha, el GC de escucha intermitente, el GC de escucha aparente y el GC de desescucha aparente. Cada una de ellas está relacionada con el modo de llevar adelante el proceso comunicativo y la experiencia de la democracia en el aula de clase. De manera correspondiente, se han inventariado los indicadores cualitativos que las evidencian, clasificados según los siguientes criterios: primero, formas de comunicar-se y de vivir la experiencia de escucha en el aula, y, segundo, formas de vivir la experiencia de la democracia en el aula. Esto se presenta en sendas tablas. 
Tabla 1. Categorías e indicadores resultantes de la actitud de escucha proactiva.

\begin{tabular}{|c|c|}
\hline $\begin{array}{l}\text { CATEGORÍA 1: } \\
\text { GC ESCUCHADOR }\end{array}$ & $\begin{array}{l}\text { INDICADORES descritos fenomenológicamente: } \\
\text { las acciones como textos (P. Ricoeur), como acciones simbóli- } \\
\text { cas (Geertz), observadas fenomenológicamente (Schutz) }\end{array}$ \\
\hline \multirow{6}{*}{$\begin{array}{l}\text { Criterio 1: Formas de co- } \\
\text { municar-se y de vivir la } \\
\text { experiencia de escucha en } \\
\text { el aula. }\end{array}$} & $\begin{array}{l}\text {-El uso de tecnologías del sonido durante la clase es mínimo; ade- } \\
\text { más, por lo regular, se acata la petición de apagarlas o guardarlas. }\end{array}$ \\
\hline & $\begin{array}{l}\text {-En general, los turnos conversacionales pueden ser coordinados por } \\
\text { el (la) docente, y por los mismos estudiantes para los propósitos } \\
\text { didácticos. }\end{array}$ \\
\hline & $\begin{array}{l}\text {-La comunicación se da en condiciones de escucha aceptables y con } \\
\text { el vocabulario para el contexto de la actividad áulica. }\end{array}$ \\
\hline & $\begin{array}{l}\text {-A pesar de que se pueden presentar desvíos ocasionales de la aten- } \\
\text { ción, por diversos motivos, cada integrante regresa al hilo del asunto } \\
\text { que se está llevando a cabo. }\end{array}$ \\
\hline & $\begin{array}{l}\text { Las relaciones maestro-estudiante se dan en un marco de respeto y } \\
\text { reconocimiento mutuos, a pesar de los naturales gajes del oficio de } \\
\text { ser maestro y de ser estudiante. }\end{array}$ \\
\hline & $\begin{array}{l}\text {-En el trabajo grupal, la conversación se concentra mayormente en } \\
\text { el compromiso con la tarea. }\end{array}$ \\
\hline \multirow{5}{*}{$\begin{array}{l}\text { Criterio 2: Formas de vivir } \\
\text { la experiencia de la demo- } \\
\text { cracia en el aula. }\end{array}$} & $\begin{array}{l}\text {-El grupo y el (la) docente administran el juego de la convivencia, en } \\
\text { beneficio del proceso enseñanza-aprendizaje. }\end{array}$ \\
\hline & $\begin{array}{l}\text {-Los llamados de atención se acatan proactivamente y los conflictos } \\
\text { que se dan, se resuelven sin consecuencias dramáticas. }\end{array}$ \\
\hline & $\begin{array}{l}\text {-Se evidencia una idiosincrasia grupal traducida en un encuentro de } \\
\text { voluntades con propósitos compartidos por la mayoría. }\end{array}$ \\
\hline & -Lo proxémico se acoge, en beneficio del cuidado de sí y del otro. \\
\hline & $\begin{array}{l}\text {-En el trabajo grupal, los integrantes coadyuvan con la autorregula- } \\
\text { ción de las interacciones. }\end{array}$ \\
\hline
\end{tabular}


Tabla 2. Categorías e indicadores resultantes de la actitud de desescucha.

\begin{tabular}{|c|c|}
\hline $\begin{array}{l}\text { CATEGORÍA 2: } \\
\text { GC DESESCUCHA }\end{array}$ & $\begin{array}{l}\text { INDICADORES descritos fenomenológicamente: } \\
\text { las acciones como textos (P. Ricoeur), como acciones simbó- } \\
\text { licas (Geertz), observadas fenomenológicamente (Schutz) }\end{array}$ \\
\hline \multirow{8}{*}{$\begin{array}{l}\text { Criterio 1. Formas de co- } \\
\text { municar-se y de vivir la } \\
\text { experiencia de escucha en } \\
\text { el aula. }\end{array}$} & $\begin{array}{l}\text {-Algunos estudiantes están pendientes del uso del celular o efectiva- } \\
\text { mente están comunicándose por este medio, o están oyendo música } \\
\text { con alguna tecnología del sonido, acciones que atraen a otros a su } \\
\text { círculo de distracción. }\end{array}$ \\
\hline & $\begin{array}{l}\text {-Los turnos conversacionales no están coordinados para los fines del } \\
\text { desarrollo de la clase, se habla de cualquier cosa en los corrillos de } \\
\text { charla, o sobre los asuntos de la clase pero de modo disperso. }\end{array}$ \\
\hline & $\begin{array}{l}\text {-En ocasiones, gritan y emplean vocabulario soez en su interacción } \\
\text { verbal. }\end{array}$ \\
\hline & $\begin{array}{l}\text {-Algunos optan por enviar mensajes escritos a otros en tiras de papel } \\
\text { doblado o arrugado, de modo furtivo o ante los ojos de los docentes. } \\
\text { Otros realizan tareas de otras asignaturas del día. Algunos optan por } \\
\text { el mutismo voluntario. }\end{array}$ \\
\hline & $\begin{array}{l}\text {-Los llamados de atención de los docentes (titular y/o practicante) } \\
\text { no son atendidos, en consecuencia el aula es un desencuentro caó- } \\
\text { tico de voces. }\end{array}$ \\
\hline & $\begin{array}{l}\text {-Se dan momentos en los que el GC está en tal intercambio caótico } \\
\text { de voces que se percibe que el (la) docente le habla al vacío. }\end{array}$ \\
\hline & $\begin{array}{l}\text { Las relaciones maestro-estudiante no se dan en un marco de respe- } \\
\text { to y reconocimiento mutuos, los gajes del oficio de ser maestro y de } \\
\text { ser estudiante no se sortean con facilidad. }\end{array}$ \\
\hline & $\begin{array}{l}\text {-Si el (la) docente no posee fuerza vocálica, su voz se pierde entre el } \\
\text { ruido, ocasionando que quienes buscan escuchar eleven la voz para } \\
\text { demandarlo. }\end{array}$ \\
\hline \multirow{5}{*}{$\begin{array}{l}\text { Criterio 2. Formas de vivir } \\
\text { la experiencia de la demo- } \\
\text { cracia en el aula. }\end{array}$} & $\begin{array}{l}\text {-Permisión del ingreso de estudiantes al aula a cualquier hora, gene- } \\
\text { rando desatención para el grupo clase. }\end{array}$ \\
\hline & $\begin{array}{l}\text {-Dejar escuchar y escuchar no está en el espectro de la apropiación } \\
\text { consciente de saberes y de la práctica individual y colectiva. }\end{array}$ \\
\hline & $\begin{array}{l}\text {-Cuando el docente titular o el practicante, } 0 \text { ambos, presionan para } \\
\text { minorar el bullicio, se logra por contados minutos y vuelve a apa- } \\
\text { recer. }\end{array}$ \\
\hline & $\begin{array}{l}\text {-Se da la tendencia a habitar el aula como espacio de socialización, } \\
\text { distante del compromiso escolar propiamente dicho. }\end{array}$ \\
\hline & $\begin{array}{l}\text {-Lo proxémico se quiebra, de modo persistente, por contactos cor- } \\
\text { porales que rayan en la expresión de la violencia física y psicológica. }\end{array}$ \\
\hline
\end{tabular}




\section{Conclusiones}

El fenómeno de la escucha humana y su desvalor, la desescucha, observados fenomenológicamente en un contexto local, han permitido proyectar unas generalizaciones que atañen a su manifestación en toda la geografía escolar. Los indicadores extraídos pueden ser hallados en cualquier institución educativa, razón por la que es dable pensar que la educación de la escucha está por hacerse en el seno escolar, para impactar en el ambiente familiar y social. Por ende, el significado de la escucha en maestros y estudiantes no es algo explícito, no se ha pensado en la escucha como un asunto académico de grandes dimensiones. Ella está en estado silvestre, se entiende que la facultad de oír nos da la escucha, pero son dimensiones diferentes: una biológica y otra cultural.

La disonancia y el déficit de la escucha no se aplican solo al campo de la democracia; lo son, primeramente, de la esencia del acto pedagógico, ya que por su naturaleza deviene en acto comunicativo y social. Esto, unido a que la escuela es un escenario para fundamentar los principios básicos de la vida en relación, hace que sea imperativa la exigencia de una educación de la escucha en estudiantes y maestros, pues, en lo que se ha explorado no se encuentra evidencia de que tanto unos como otros la hayan recibido.

En consecuencia, uno de los campos de investigación más prometedores para el estudio del lenguaje y la didáctica de todas las disciplinas, es sin duda el fenómeno de la escucha; será la contracorriente de esta cultura del ruido y la depredación que mora la vida actual. Para la pedagogía, investigar e intervenir será una labor encomiable, dado que el desarrollo de la habilidad de escucha hace posible el adentramiento del sujeto humano en la cultura (téngase presente que el primer órgano de la percepción que pone en contacto al feto con el mundo exterior es el oído).

Así las cosas, la actitud de escucha como postura ético política constituye el fundamento de la conversación pedagógica y de toda experiencia de la democracia en el aula de clase -pero también en la familia y en la comunidad-, razón que está justificando, en los actuales tiempos, el esfuerzo de muchos investigadores de diferentes campos por ahondar en los enigmas de tan indispensable habilidad: el escuchar humano.

En suma, sin una educación para la escucha, que lleve al estudiante y al maestro como sujetos discursivos a optar por una postura ética y política mediante su actitud de escucha frente a la enseñanza y el aprendizaje, es poco probable que se den la comunicación pedagógica y la experiencia de la democracia en el aula de clase, y que sin actitud de escucha todo trabajo en el aula es inútil para los propósitos educativos del desarrollo humano y social. 


\section{Referencias}

Aguilar, M. (2007). Reflexiones acerca de la habilidad de escuchar en el proceso docenteeducativo. Recuperado de: http://www.efdeportes.com/efd106/la-habilidad-escuchar-en-elproceso-docente-educativo.htm

Albarracín, D., Johnson, B. T., \& Zanna, M. P. (2005). The handbook of attitudes. Mahwah: Lawrence Erlbaum.

Bickford, S. (1996). The dissonance of democracy: Listening, Conflict, and Citizenship. Recuperado de http://www.amazon.com/The-Dissonance-Democracy-Listening-Citizenship/ dp/0801483778\#reader_0801483778

Bolio, A. P. (2012). Husserl y la fenomenología trascendental: Perspectivas del sujeto en el Siglo XX. Reencuentro, (65), 20-29. Recuperado de: http://www.redalyc.org/pdf/340/34024824004. pdf

Dawkins, R. (2000). El gen egoísta. Barcelona: Salvat.

Dobson, A. (2014). Listening for democracy: Recognition, Representation, Reconciliation. Recuperado de: http://www.amazon.co.uk/Listening-Democracy-RecognitionRepresentation-Reconciliation/dp/0199682453\#reader_0199682453

Dobson, A. (2012). Listening: The new democratic déficit. Political Studies, 60(4), 843-859. Recuperado de: http://ecpr.eu/filestore/paperproposal/bf8c40cd-4bf0-4c4a-a73f83b0cb00f689.pdf

Echeverría, R. (2007). Ontología del lenguaje. Buenos Aires: Granica.

Gauquelin, F. (1972). Saber comunicarse. Bilbao: Mensajero.

Geertz, C. (2003). La interpretación de las culturas. Barcelona: Gedisa.

Habermas, J. (1996). Teoría de la acción comunicativa: complementos y estudios previos. México: Rei.

Hernández, R., Fernández, C., \& Baptista, P. (2010). Metodología de la investigación (5a. ed.). México: McGraw-Hill.

Laverty, M. (2011). ¿Can you hear me now? Jean-Jacques Rousseau on listening education. Educational theory, 61(2), 155-169.

Lucio, R. (2005). Del aprendizaje significativo al aprendizaje dialógico. En: Nuevo Diario, Managua (31, jul. 2005); p. Opinión. Recuperado de: http://impreso.elnuevodiario.com. ni/2005/07/31/opinion). 
Marco, Á. (2009). El silencio en la enseñanza: Las bieles de un sistema educativo delirante. Barcelona: PPU.

Maykut, P., \& Morehouse, R. (1999). Investigación cualitativa: Una guía práctica y filosófica. Barcelona: Hurtado Ediciones.

Motta, H. (2016). El valor del silencio en la cultura escolar. Cuadernos de Lingüística Hispánica, (28), 167-187. doi: http://dx.doi.org/10.19053/0121053X.4914

Plutarco (1985). Obras morales y de costumbres (Moralia), Tomo I. Madrid: Gredos.

Quiroga, Y. (2005). La falta de atención en el aula. Recuperado de: http://www.diariodecuyo.com. ar/participar/new_blogopin.php?blog_id=14\&blogcomen_id $=171$

Rice, S. (2011). Toward an Aristotelian conception of good listening. Educational theory, 61(2), 141-153.

Ríos, T. (2013). La bermenéutica reflexiva en la investigación educacional y social: Articulaciones entre Paul Ricoeur y la Pedagogía Crítica de Paulo Freire. Manizales: Centro de Publicaciones Universidad de Manizales.

Ríos, T. (2005). La bermenéutica reflexiva en la investigación educacional. Recuperado de: http://www.facso.uchile.cl/publicaciones/enfoques/09/Rios_N7_2005.pdf

Santibáñez, C. (2011). Teoría social y memes. Recuperado de: https://dialnet.unirioja.es/servlet/ articulo? codigo $=4051179$

Segura, J. A. (2010). El escuchar, la habilidad lingüística olvidada. Recuperado de: http:// www.buenastareas.com/ensayos/El-Escucha-La-Habilidad-Ling\%C3\%BC\%C3\%ADsticaOlvidada/756390.html

Schütz, A. (1979). El problema de la realidad social. Buenos Aires: Amorrortu.

Schutz, A., \& Luckmann, T. (2003). Las estructuras del mundo de la vida. Buenos Aires: Amorrortu.

Tomatis, A. (1996). El fracaso escolar. Barcelona: Bibliaria.

Torralba, F. (2007). El arte de saber escuchar. Lleida: Milenio.

Ubini, L. (2007). ¿Qué es la pedagogía de la escucha? Recuperado de: http://mariasoledadlagos. blogia.com/2007/051401-que-es-la-pedagogia-de-la-escucha.php

Waks, L. (2011). John Dewey on listening and friendship in school and society. Educational theory, 61(2), 191-205.

Young, R. (1993). Teoría crítica de la educación y discurso en el aula. Barcelona: Paidós. 